\title{
Salvage High Dose Rate Brachytherapy For Locally Recurrent Prostate Cancer
}

\author{
Solodkiy VA, Pavlov AY, Tsybulskiy AD*, Dzidzaria AG and Pchelintsev AS \\ Russian Research Center for Radiology of the Russian Ministry of Health, Russia
}

Received: 眥 January 01, 2019; Published: 制 January 18, 2019

*Corresponding author: Alexei Tsybulskiy, Russian Research Center for Radiology of the Russian Ministry of Health, Russia

Abbreviations: PC: Prostate Cancer; HDRBT: High Dose Rate Brachytherapy; EBRT: External Beam Radiation Therapy; LDR: Low Dose Rate Brachytherapy; PSA: Prostatic Specific Antigen

\section{Introduction}

Research study of salvage interstitial radiotherapy of prostate cancer (PC) recurrence was started in the end of the XX century. Lately more and more attention has been paid to the high-dose rate brachytherapy (HDR-BT) as a way of achieving local tumor control. According to a number of authors the preliminary evidence of HBRBT revealed a high efficiency of local PCR control at the trough level of toxic response from critical pelvic organs [1-3].

\section{Materials and Methods}

The research includes 28 patients aged 53 to 78 years old (average age is 66 years old) with histologically verified PC recurrence. Within the period 2015 - 2017 all the patients got a life-saving HDR-BT in the Russian Scientific Center of Roentgenoradiology in Moscow. Brachytherapy was carried out as 2 fractions with the single tumor dose of 12,5 Gy. There was a twoweek gap between fractions with the total tumor dose of $25 \mathrm{~Gy}$. The follow-up period is 9 to 36 months. The study was approved by the Ethics Committee of the Russian Research Center for Radiology of the Russian Ministry of Health. All patients gave written informed consent. Five cases of recurrence were detected after external beam radiation therapy (EBRT). Six cases - after the combination of highdose rate radiotherapy and brachytherapy LDR/HDR (HDR 10 Gy/LDR 110 Gy + HBRT 46 Gy). Eleven cases - after low-dose rate brachytherapy (LDR). Five patients - after radical prostatectomy (RP). One patient - after Hi-Fu. The period from the performed background therapy to the recurrence was 6 to 72 months (30 months on an average). The patients were divided into following risk groups (NCCN Classification)
a. Low risk - 3 patients;
b. Intermediate risk - 12 patients;
c. High risk - 8 patients;
d. Very high risk - 5 patients.

Results

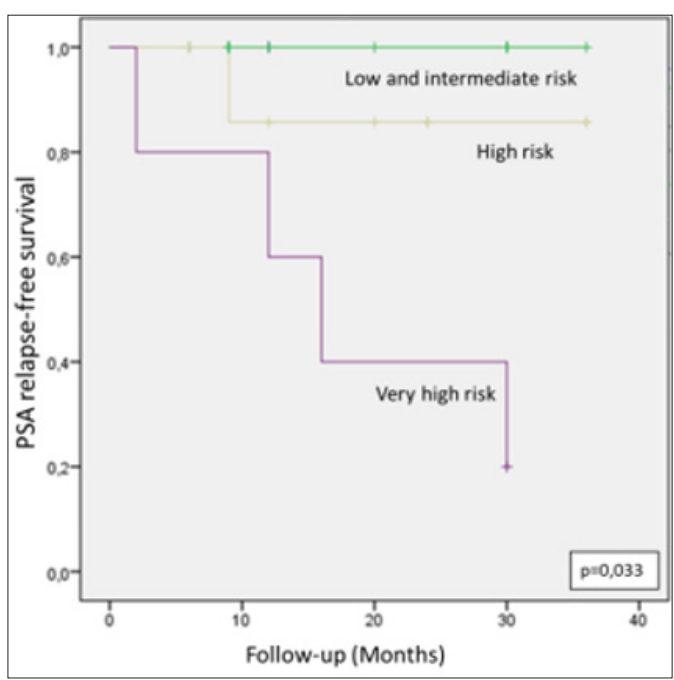

Figure 1: BFSR in different risk groups of prostate cancer progression.

Overall biochemical free survival rate (BFSR) is $82.1 \%$. There are 5 people having a growing prostatic specific antigen (PSA) 
while the case follow-up. Four recurrence cases with metastases in lymph nodes and bones were brought out as a result of 68GaPSMA PET examination. There is 1 case of a confirmed local tumor recurrence. Significant factors of the disease progression after salvage brachytherapy are: risk group (see the diagram below) Figure 1, pretreatment PSA high, time line from the background therapy to biochemical recurrence uprise and PSA level if there's prostate cancer recurrence after the background therapy. Gastrointestinal toxic response was non-critical. After the LDR-BT cancellation there were 2 patients who had delayed genitourinary toxic response of the third degree.

\section{Conclusion}

HDR-BT has revealed itself to be a highly effective method of achieving local tumor control in relation to the patients with local recurrence of prostate cancer. Low profile of gastrointestinal and genitourinary toxic responses points out HDR-BT among any other methods of salvage prostate cancer therapy. The patients with clinical $\mathrm{T} 3 \mathrm{~b}$ disease state had the most frequent disease progression. It's important to notice that special attention should be paid to the patients with local prostate cancer recurrence after LDR-BT. These patients have much higher risks of genitourinary toxic response progression.

\section{Purpose}

This research work is aimed at the primary analysis of prostate cancer treatment referring to the patients who have experienced HDR-BT after a confirmed locally recurrent tumor having been treated with diverse treatment modes.

\section{References}

1. Maenhout M, Vulpen M, Moerland M, Max Peters, Richard Meijer, et al. (2017) Second salvage high-dose-rate brachytherapy for radiorecurrent prostate cancer. J Contemp Brachytherapy 9(2): 161-166.

2. Tran H, Kwok J, Pickles T, Tyldesley S, Black PC, et al. (2014) Underutilization of local salvage therapy after radiation therapy for prostate cancer. Urol Oncol 32(5): 701-706.

3. Zamboglou C, Rischke HC, Meyer PT, Knobe S, Volgeova Neher N, et al. (2016) Single fraction multimodal image guided focal salvage highdose-rate brachytherapy for recurrent prostate cancer. J Contemp Brachytherapy 8(3): 241-248.

\section{ISSN: 2574-1241}

DOI: $10.26717 / B J S T R .2019 .13 .002379$

Tsybulskiy AD. Biomed J Sci \& Tech Res

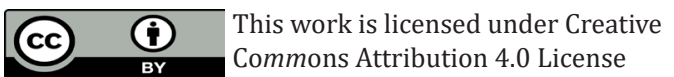

Submission Link: https://biomedres.us/submit-manuscript.php

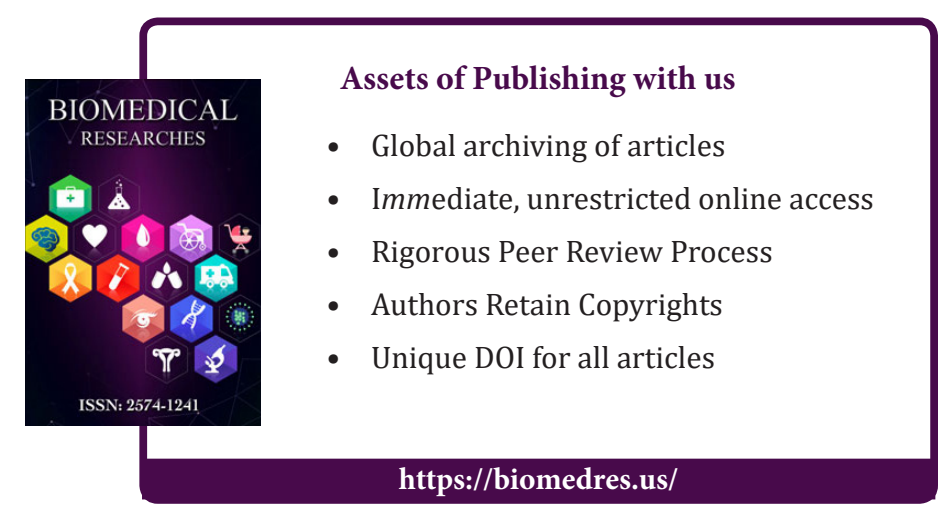

